\title{
IDENTIFICAÇÃO DO PADRÃO DE DISTRIBUIÇÃO DE MACRÓFITAS AQUÁTICAS EMERGENTES NO BANHADO DO TAIM-RS-BRASIL, FRENTE A DIFERENTES CONDIÇÕES HIDROLÓGICAS
}

\author{
IDENTIFICATION OF THE DISTRIBUTION PATTERN OF EMERGING AQUATIC \\ MACROPHITES IN THE BANHADO OF TAIM RELATED TO DIFFERENT HYDROLOGICAL \\ CONDITIONS
}

\section{Cristiano Niederauer da ROSA ${ }^{1}$, Rutinéia TASSI ${ }^{2}$, Daniel Gustavo Allasia PICCILLI ${ }^{2}$, Waterloo PEREIRA FILHO ${ }^{1}$, Jean Ricardo FAVARETTO ${ }^{3}$, Jéssica Ribeiro FONTOURA ${ }^{2}$ \\ ${ }^{1}$ Universidade Federal de Santa Maria, Departamento de Geociências. Email: cristianonr@hotmail.com \\ ${ }^{2}$ Universidade Federal de Santa Maria, Departamento de Engenharia Sanitária e Ambiental. Emails: rutineia@gmail.com, dallasia@gmail.com,waterloopf@gmail.com, jessica.ribeirofontoura@gmail.com \\ ${ }^{3}$ Universidade Federal de Santa Maria, Departamento de Engenharia Civil. Email: jean.favaretto@gmail.com}

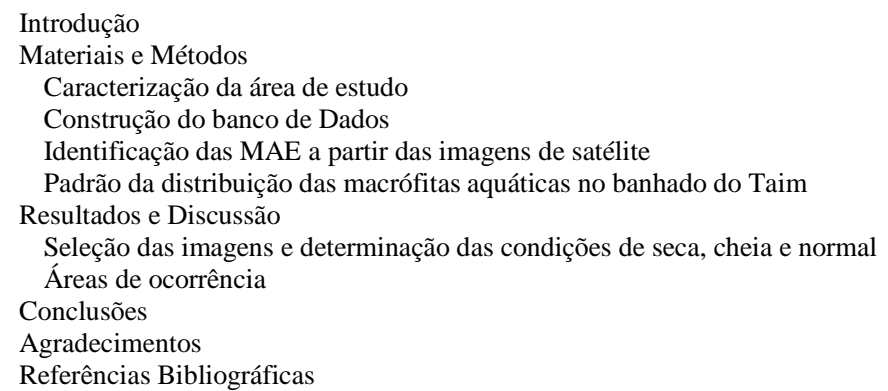

RESUMO - O Banhado do Taim, importante área úmida no sul do Rio Grande do Sul, Brasil ocupa cerca de 53\% da área total da Estação Ecológica do Taim, uma Unidade de Conservação Federal. Sua bacia de contribuição tem seus usos compartilhados, principalmente entre a conservação da biodiversidade e irrigação. Esta última atividade altera o regime hidrológico do Banhado, característica fundamental para a manutenção da biodiversidade local. O presente trabalho avaliou, por meio de técnicas de Sensoriamento Remoto e Geoprocessamento, que incluíram o processamento digital e classificação de imagens multitemporais dos sensores TM e ETM do satélite Landsat, a influência das condições hidrológicas na dinâmica de Macrófitas Aquáticas Emergentes (MAE) no banhado. Para isso, foram selecionadas três espécies de MAE, Z. bonariensis, S. californicus e S. giganteus, consideradas indicadores biológicos, passíveis de identificação em imagens Landsat, que foram analisadas quanto a sua distribuição em condições hidrológicas de cheia, seca e normal. Os resultados indicam que as MAE S. californicus e Z. bonariensis são mais vulneráveis à condições de cheia pois, nesta situação, verificou-se, em algumas imagens, uma redução de 15,86\% nas áreas de Z. bonariensis e a não ocorrência de S. californicus. Portanto, as alterações do regime hidrológico do Banhado do Taim (cheia e seca) alteram a distribuição das MAE e, consequentemente, a biodiversidade do local.

Palavras-chave: Sensoriamento Remoto; Macrófitas Aquáticas Emergentes; Áreas Úmidas; SIG.

\begin{abstract}
The Taim wetland is an important humid area located in the state of Rio Grande do Sul, Brazil, that represents 53\% of the federally-administered conservation unit Taim Ecological Station. Its contribution watershed has uses shared mainly between biodiversity conservation and irrigation. The irrigation activity changes the wetland hydrological stream, which is a key feature for local biodiversity maintenance. Thus, the main purpose of this study was to evaluate through Remote Sensing and GIS, including digital processing and classification of multitemporal images of the TM and ETM Landsat satellite sensors, the influence of hydrological conditions in the Water Emerging Macrophytes (WEM) dynamic. In order to do that, three species of WEM, considered biological indicators and susceptible of identification by Landsat images, were selected. So, the distribution of Z. bonariensis, S. californicus and $S$. giganteus was analyzed through flood, drought and normal hydrological conditions. The results indicate that the WEM S. californicus and $Z$ bonariensis are more vulnerable to flood conditions, because in this situation some images showed that there was a $15.86 \%$ reduction in the areas of $Z$. bonariensis, and no occurrence of in $S$. californicus. Therefore, the changes caused in the hydrological regime of Taim Wetland (flood and drought) alter the WEM distribution, and consequently alter the local biodiversity.
\end{abstract}

Keywords: Remote Sensing; Emerging Macrophytes;Wetlands; GIS.

\section{INTRODUÇÃO}

Para o funcionamento adequado dos ecossistemas, bem como a sobrevivência dos seres vivos é primordial não só a disponibilidade hídrica, mas também, sua qualidade. No entanto, à medida em que as populações e as atividades industriais e agrícolas aumentam, aumenta também a ameaça à integridade dos recursos hídricos (ANA, 2011; Tundisi, 2006; Silva \& Porto, 2003). Soma-se a este fato, as constatações publicadas nos relatórios do Painel Intergovernamental sobre Mudanças Climáticas (IPCC, 2007, 2014,), que desde 2007 destacavam evidências de que os sistemas 
biológicos e físicos vinham sofrendo com o aquecimento antropogênico ao longo das últimas três décadas, especialmente na hidrologia, devido à ação da temperatura sobre os processos de evapotranspiração e precipitação (IPCC, 2007; Pachauri \& Meyer, 2014).

Um importante aliado no combate ao aquecimento global e à poluição dos recursos hídricos são os ecossistemas de áreas úmidas, que, por serem ambientes de alta biodiversidade, prestam serviços ambientais que beneficiam os seres humanos (Esteves, 1988; Motta-Marques, 1997; Tassi, 2008; Moraes, 2011), ajudando na manutenção dos processos ambientais. Alguns exemplos dos benefícios proporcionados por estes ecossistemas são citados por Burger (2000) e Chomenko (2007), como: estocagem e purificação da água; recarga do lençol freático; regulagem do clima local; manutenção da biodiversidade; regulagem dos ciclos biogeoquímicos; estocagem de carbono; proteção de zonas costeiras à elevação do nível do mar; controle da erosão; absorção de grandes volumes de chuva.

A vegetação característica das áreas úmidas são espécies de macrófitas aquáticas (Pott et al., 2012), sendo sua permanência durante todo o ano, responsável por manter a alta heterogeneidade de habitats, com consequente elevação da biodiversidade animal do local (Agostinho, 2000). No entanto, a distribuição das macrófitas no ambiente aquático é variável, e depende do grau da adaptação da espécie, podendo ocorrer em regiões mais rasas ou mais profundas, sendo, por isso, classificadas em emersas, flutuantes, submersas enraizadas, submersas livres e com folhas flutuantes (Esteves, 1988). Nesse contexto, pode-se dizer que a frequência, duração e tempo no qual a área úmida está saturada (hidroperíodo) (Motta Marques et al., 1997) e seus padrões de fluxo são características fundamentais para a manutenção da biodiversidade de uma área úmida. Assim, qualquer atividade que altere este comportamento torna este tipo de ecossistema vulnerável, em razão da perda de habitats e espécies (Motta-Marques, 1997; Tassi, 2008; Zedler \& Kercher, 2005).

Diversos estudos realizados no Parque Nacional Everglades, Estados Unidos
(Armentano et al., 2006; Todd et al., 2010; Foti et al., 2013; Sah et al., 2013), já comprovaram a influência dos níveis d'água em comunidades de macrófitas. No que se refere ao monitoramento de vegetação, Carvalho \& Carvalho (2012) citam o Sensoriamento Remoto como importante ferramenta no mapeamento e acompanhamento do estado da vegetação. Nos últimos anos, pode-se observar uma grande quantidade de estudos que utilizaram essa ferramenta em áreas úmidas, para avaliar a distribuição de macrófitas (Silva et al., 2010; Fragal et al., 2012; Ward et al., 2014).

No Brasil, o uso do solo tem ameaçado, especialmente, as áreas úmidas como o Banhado do Taim, localizado no interior da Unidade de Conservação Federal, denominada Estação Ecológica do Taim (ESEC - Taim). Uma vez que boa parte da bacia de contribuição do Banhado do Taim fica fora da ESEC-TAIM, são relatados conflitos históricos pelo uso da água entre à agricultura e a preservação da biodiversidade (Tassi, 2008; Sete, 2010), o que tem refletido na baixa capacidade de recuperação do ecossistema, agravado pelo fato da precipitação média anual ser muito semelhante à evaporação média anual (Panessa et al., 1989). As marcas destes conflitos são encontradas na região, através de alterações morfohidrográficas, decorrentes da expansão urbana e de práticas agrícolas vinculadas às lavouras de arroz irrigado (Simon \& Silva, 2015).

Alguns estudos (Tassi, 2008; Xavier, 2015) investigaram meios de aprimorar o gerenciamento do ecossistema do Banhado do Taim com a utilização de indicadores biológicos, como as macrófitas aquáticas, que funcionam como atributos que refletem o status ambiental ou a condição de sustentabilidade do ecossistema para definir condições hidrológicas mínimas a serem preservadas para a manutenção de sua biodiversidade (Araújo \& Monteiro, 2007). Este tipo de estudo com macrófitas é possível sempre que há o conhecimento de como a vegetação corresponde às alterações nos níveis d’água, concomitantemente com a análise da dinâmica da vegetação.

Nesse contexto, as técnicas de sensoriamento remoto viabilizam a quantificação das alterações 
na dinâmica da vegetação em função de alterações nos níveis d'água, visto que o interior das áreas úmidas normalmente é local de difícil acesso. Exemplos da eficácia desta aplicação são encontrados em Mesquita, (2013) e Fragal et al. (2012), entre outros.

Neste contexto, o presente trabalho analisou, por meio de técnicas de processamento digital e classificação de imagens multitemporais dos sensores TM e ETM do satélite Landsat, a influência das condições hidrológicas na dinâmica de Macrófitas Aquáticas Emergentes (MAE) consideradas indicadores biológicos do Banhado do Taim.

\section{MATERIAIS E MÉTODOS}

\section{Caracterização da Área de Estudo}

Com área de aproximadamente 191,87 Km², o Banhado do Taim está localizado próximo ao extremo Sul do Brasil, especificamente no Estado do Rio Grande do Sul, Brasil, entre os municípios de Rio Grande e Santa Vitória do Palmar, ao norte da lagoa Mangueira, em uma estreita faixa compreendida entre a lagoa Mirim e o oceano Atlântico (Figura 1).

Regionalmente, as áreas úmidas são chamadas de "banhados”, termo que provém do espanhol, e se refere a áreas sujeitas à inundação permanente com pequena lâmina de água, diferentemente da conceitualização mais ampla sobre a definição do termo áreas úmidas (Burger, 2000).

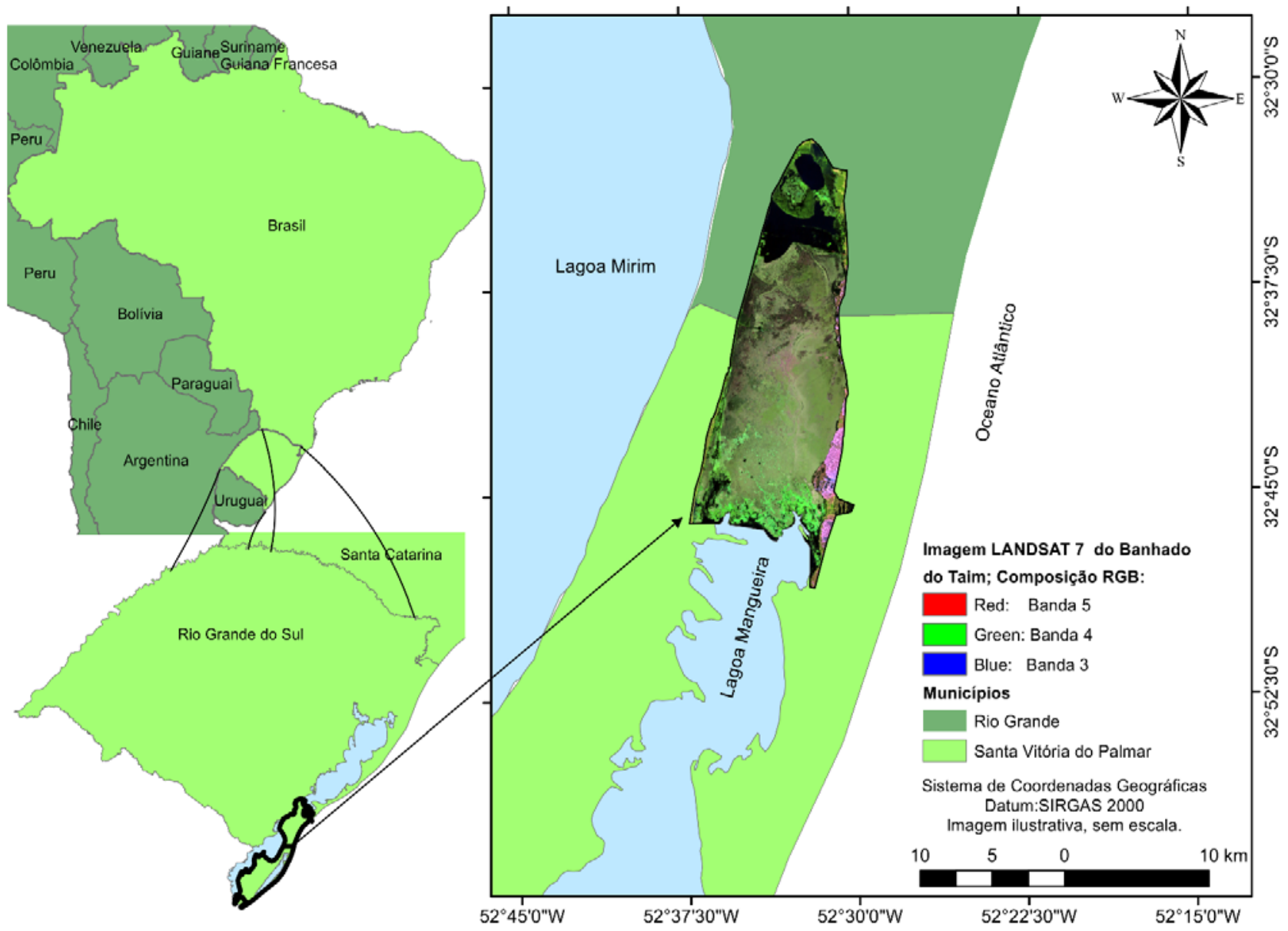

Figura 1 - Localização do Banhado do Taim.

A área de estudo pertence à Bacia Hidrográfica Mirim-São Gonçalo, a qual faz parte da região hidrográfica do Atlântico Sul, conforme a classificação da Agência Nacional de Águas (ANA, 2013). A maior parcela de entrada de água no Banhado do Taim ocorre por meio das precipitações na sua bacia hidrográfica, e o escoamento advindo da lagoa Mangueira, principal fonte de alimentação de água, localizada ao sul do Banhado do Taim.

As saídas de água ocorrem basicamente por evaporação, irrigação e, quando o nível d'água está alto, através do escoamento para a Lagoa Mirim, mediante um sistema de canais e comportas, localizado ao norte do banhado, caracterizando um sistema regido essencialmente 
por níveis d'água (Paz, 2003; Villanueva, 2003).

A temperatura média no local é de $23^{\circ} \mathrm{C}$ durante o mês mais quente (Janeiro) e $13^{\circ} \mathrm{C}$ durante o mês mais frio (Julho). As precipitações são bem distribuídas durante o ano todo, tendo um leve aumento nos meses de inverno. Estas características incluem a região de estudo na classe de clima subtropical Ia, pouco úmido, com inverno frio e verão fresco (Rossato, 2011).

Como já mencionado, parte deste banhado pertence à Unidade de Conservação Federal criada em 1978, denominada ESEC-Taim, local que desde 1986 foi considerado área de proteção ambiental brasileira pelo Decreto $n^{0} .92 .963$ (Paz et al., 2003).

A ESEC-Taim caracteriza-se por sua alta biodiversidade, sendo que aproximadamente 53\% de sua área é classificada como região de banhado, onde foram identificadas um total de 331 espécies de macrófitas aquáticas (Burger, 2000), 78 espécies de aves aquáticas (Burger \& Ramos, 2007), 63 espécies de peixes (Garcia et al., 2006; Correa et al., 2011), 18 espécies de anfíbios (Gayer et al., 1988) e 21 espécies de répteis (Gomes et al., 1982).

\section{Construção do Banco de Dados}

Com base nos estudos de Tassi (2008) e Xavier (2015), foram escolhidas três espécies de MAEs, reconhecidas como indicadores biológicos do Banhado do Taim (Z. bonariensis, $S$. californicus e $S$. giganteus), que por seus extensos estandes e predominância são identificáveis em imagens dos sensores TM e ETM do satélite Landsat.

A utilização das imagens destes sensores justifica-se pela vasta série histórica disponibilizada gratuitamente, e com boa resolução espectral, temporal e espacial (Costa \& Souza Junior, 2005; Lamparelli et al., 2008). Portanto, nesse estudo foram selecionadas imagens dos sensores TM e ETM que atendessem a dois requisitos: ausência de nuvens e pertencer ao período compreendido entre os anos de 1984 até 2003, em razão da disponibilidade de dados hidrológicos (série de níveis d’água do Banhado do Taim).

A seleção de imagens foi realizada no banco de dados do USGS Global Visualization Viewer (http://earthexplorer.usgs.gov/) e agrupadas em três condições hidrológicas: cheia, seca e normal. A referência para esta separação foi obtida por meio da análise harmônica da série de nível d'água do Banhado do Taim, para o período de janeiro de 1960 a dezembro de 2003 (Tassi, 2008).

Após o cálculo da média dos máximos e mínimos harmônicos, foi definida primeiramente a condição normal (intervalo entre o máximo e mínimo harmônico). Deste modo, imagens pertencentes a meses com cotas d'água abaixo e acima da condição normal, foram consideradas representativas de condição de seca e cheia, respectivamente.

As imagens selecionadas passaram por um pré-processamento, realizado por meio da ferramenta Semi Automatic Classification Plugin (SCP) (Congedo et al., 2013), que visou a correção dos efeitos atmosféricos pelo método de subtração do objeto escuro (DOS1). Neste mesmo plugin foi realizada uma composição entre todas as bandas do Landsat, com exceção das bandas do IR (infravermelho) termal e pancromática, dando origem a um arquivo imagem multibanda. A partir deste arquivo, foi possível a realização de diversas combinações, responsáveis por aumentarem as possibilidades de diferenciação entre os alvos, propiciando também ao classificador digital de imagens, uma maior faixa do espectro eletromagnético, para a identificação das classes de uso e cobertura da terra.

Ainda, foram realizadas correções geométricas diretamente nas composições das bandas Landsat, tendo como referência as cartas topográficas em escala 1: 50.000, obtidas no site da Diretoria de Serviço Geográfico do Exército (DSG). Para otimizar os processos utilizados nos cálculos de áreas, foi adotado como sistema de referência, as coordenadas Universal Transversa de Mercator (UTM) Fuso 22 Sul, tendo como Datum de referência o SIRGAS 2000.

A seguir, as imagens foram recortadas nos limites do Banhado do Taim e submetidas ao processo de classificação automática supervisionada para a identificação das três espécies de MAE, para posterior sequência de processamento, conforme fluxograma apresentado na figura 2.

\section{Identificação das MAE a partir das Imagens de Satélite}

O procedimento de identificação das MAE nas imagens deu-se por meio da classificação supervisionada no programa ArcGIS 10.3 (ESRI, 2015), utilizando o Model Builder Supervised 
Classification With Cleanup, parte da caixa de ferramentas Envi. Esta ferramenta tem como dados de saída um arquivo vetorial das classes atribuídas na imagem (Figura 2A). O algoritmo classificador utilizado foi o de Máxima Verossimilhança, no qual foram consideradas as classes: i) água; ii) Scirpus giganteus; iii) Scirpus californicus; iv) Zizaniopsis bonariensis; v) não identificada (esta classe representa as macrófitas com refletância diferente das três analisadas no presente estudo) e; vi) dunas. Para a obtenção das amostras de cada classe, foram consideradas as áreas de ocorrência da vegetação determinadas por Giovannini (2004), Guasselli (2005), Ferreira (2005), Tassi (2008), e Xavier (2015), que usaram dados de campo.

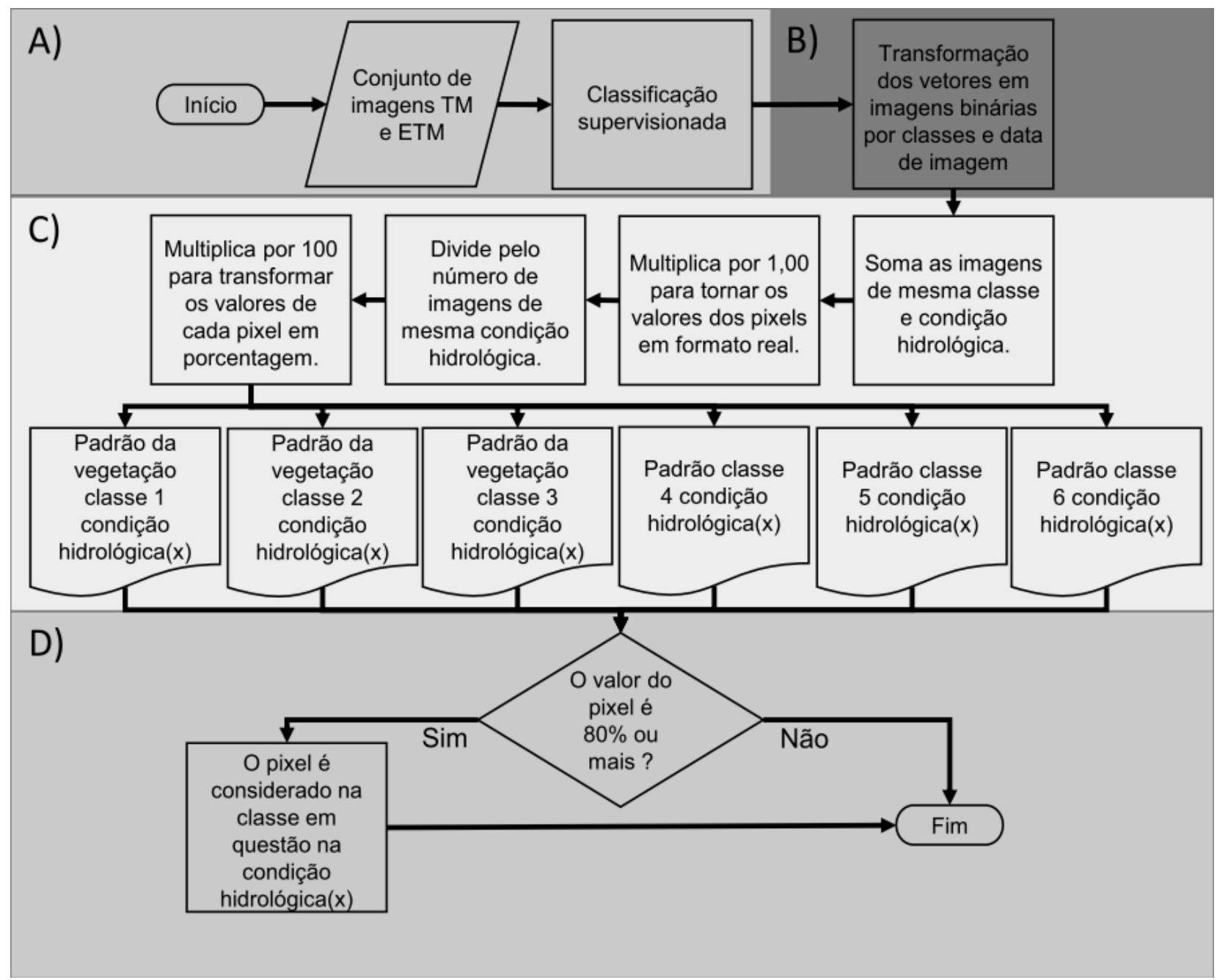

Figura 2 - Fluxograma dos processos realizados para a geração do padrão de distribuição das MAE.

Posteriormente, foram geradas imagens binárias para cada classe (Figura 2B), em que pixels representativos da classe em questão assumiram valores um, e zero para as demais classes. Assim, cada uma das 38 imagens analisadas deu origem a mais seis imagens binárias (uma para água, uma para cada classe de MAE, uma para não identificada e uma para dunas).

\section{Padrão da distribuição das Macrófitas Aquáticas do Banhado do Taim}

Para a estimativa do padrão de distribuição espacial médio de cada classe estudada e, em particular das MAE's, foi determinada uma nova imagem contendo o valor médio de todas as imagens binárias por classe.

Deste modo, ao fim do processo foi gerada uma imagem classificada por classe e condição hidrológica (seca, normal, cheia), sendo que cada uma apresenta valores entre 0 e $100 \%$ indicando a presença das diferentes classes estudadas (Figura 2C).

As áreas de ocorrência das classes de interesse (MAE e água) foram determinadas considerando apenas os pixels que pertencessem a cada uma destas classes em $80 \%$, ou mais, das imagens representativas da condição em questão (Figura 2D). 


\section{RESULTADOS E DISCUSSÃO}

Seleção das Imagens e determinação das condições de seca, cheia e normal

O período considerado no estudo permitiu o uso de 38 imagens dos sensores TM e ETM+ do satélite Landsat. O intervalo de variação dos níveis d'água no Banhado Taim, considerados na condição normal foi entre 2,11m e 3,69m; assim, valores menores que $2,11 \mathrm{~m}$ representam uma condição de seca e, acima de 3,69 m de cheia. Entre as imagens selecionadas, sete representaram a condição de seca, seis de cheia e 25 da condição normal.

A figura 3 apresenta as datas de aquisição das imagens juntamente com o histórico de nível d’água mensal encontrados no Banhado do Taim. Na tabela 1 são apresentadas as datas das imagens utilizadas, acompanhadas de seu respectivo nível d’água e condição hidrológica, indicada pelas letras c (cheia), n (normal), s (seca).

Entre as imagens enquadradas na condição de seca, três são de meses de inverno, uma de primavera, uma de outono e uma de verão. Dentre as seis de cheia, quatro são de inverno, uma de primavera e uma de outono. Nas imagens da condição normal, têm-se nove nos meses de inverno, seis da primavera, cinco do verão e sete de outono.

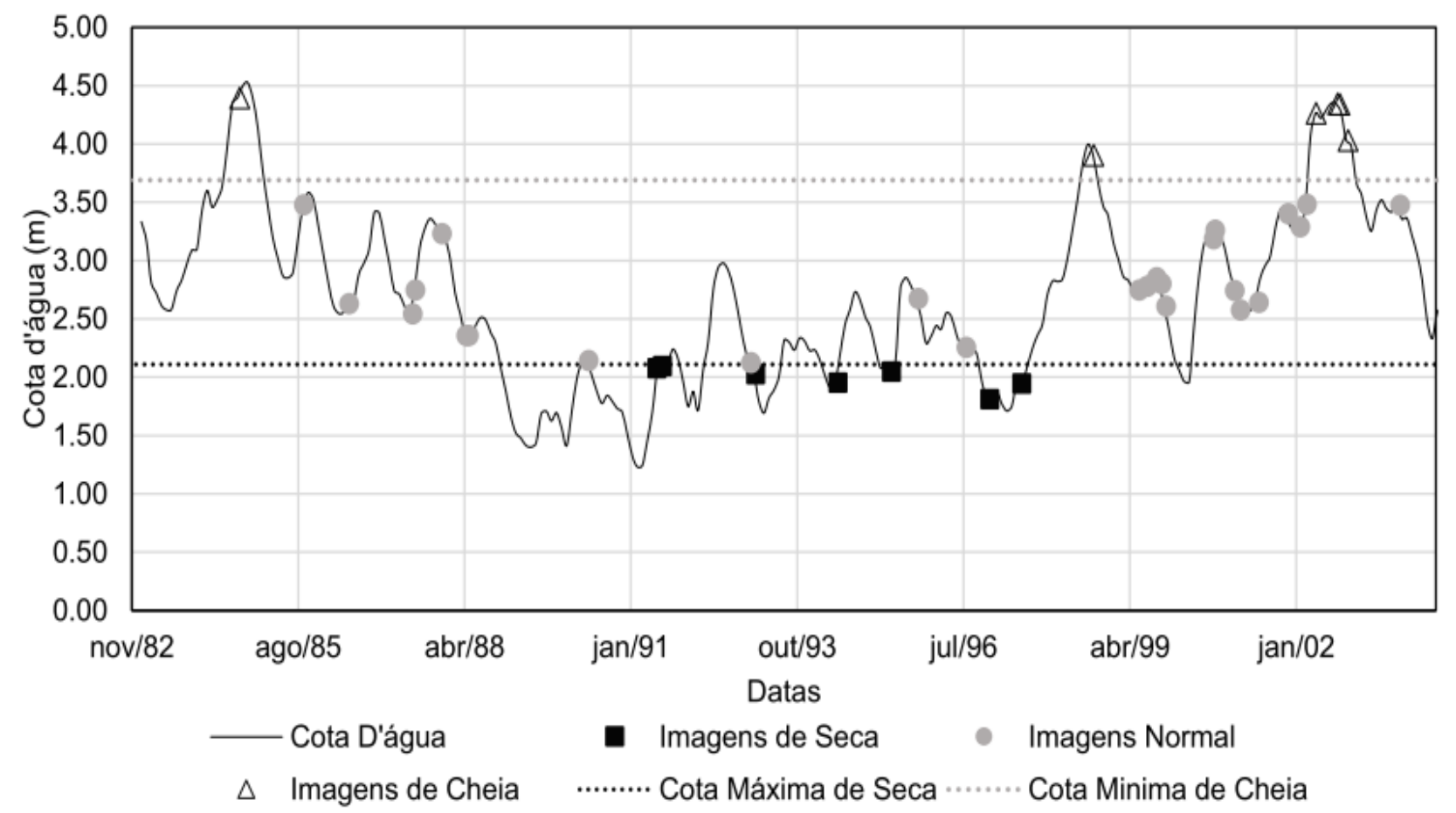

Figura 3 - Série de nível de água do Banhado do Taim juntamente com as datas das imagens Landsat utilizadas no estudo. Fonte: baseado em Tassi (2008).

\section{Áreas de Ocorrência}

Na condição de seca (Figuras 4 A e D), as áreas classificadas como água aparente no Banhado do Taim correspondem a cerca de $5,65 \%$ (1.106,92 ha), sendo este valor ligeiramente maior que na condição normal (Figuras 4 B e E). Este fato é atribuído à presença de macrófitas flutuantes, não consideradas no presente estudo que, sob condição de seca tem sua área de ocorrência reduzida, tornando as áreas com água mais visíveis nas imagens desta condição. Este tipo de macrófita movimenta-se livremente com o fluxo das águas no interior do Banhado do
Taim, sendo observadas em maior quantidade, principalmente entre imagens do fim da primavera e início do outono, meses com altas temperaturas (Figuras $4 \mathrm{~B}$ e E). Corroborando com esta constatação, Freedman \& Lacoul (2006) e Antunes et al. (2012) citam que fatores como a temperatura, correntes, nível da água e radiação solar são fundamentais para a abundância desse tipo de macrófita nos ambientes aquáticos.

Nos meses de cheia as lâminas de água ocuparam boa parte do Banhado do Taim, chegando a cerca de 16,35\% (3.202,27 ha) da área total do Banhado do Taim (Figuras $4 \mathrm{C}$ e F). 
Tabela 1 - Data das Imagens e seus respectivos níveis d’água médio mensal do Banhado do Taim. Os índices c, n, s informam a condição hidrológica a qual a imagem representa (cheia, normal e seca respectivamente).

\begin{tabular}{|c|c|c|}
\hline Sensor & Data da imagem & Cota d'água \\
\hline $\mathrm{TM}$ & $14 / 08 / 1984$ & $4,40^{\mathrm{c}}$ \\
\hline TM & 02/09/1985 & $3,48^{n}$ \\
\hline TM & $01 / 06 / 1986$ & $2,63^{n}$ \\
\hline TM & 20/06/1987 & $2,55^{n}$ \\
\hline TM & 06/07/1987 & $2,75^{n}$ \\
\hline TM & $13 / 12 / 1987$ & $3,23^{n}$ \\
\hline TM & 05/05/1988 & $2,36^{n}$ \\
\hline TM & $21 / 05 / 1988$ & $2,36^{\mathrm{n}}$ \\
\hline TM & $11 / 05 / 1990$ & $2,14^{\mathrm{n}}$ \\
\hline TM & $01 / 07 / 1991$ & $2,07^{\mathrm{s}}$ \\
\hline TM & 02/08/1991 & $2,09^{s}$ \\
\hline TM & 11/01/1993 & $2,12^{n}$ \\
\hline TM & $12 / 02 / 1993$ & $2,02^{\mathrm{s}}$ \\
\hline TM & 23/06/1994 & $1,95^{\mathrm{s}}$ \\
\hline TM & 09/05/1995 & $2,04^{\mathrm{s}}$ \\
\hline $\mathrm{TM}$ & 16/10/1995 & $2,68^{n}$ \\
\hline $\mathrm{TM}$ & 30/07/1996 & $2,26^{\mathrm{n}}$ \\
\hline TM & $21 / 12 / 1996$ & $1,81^{\mathrm{s}}$ \\
\hline TM & $01 / 07 / 1997$ & $1,94^{\mathrm{s}}$ \\
\hline TM & $06 / 09 / 1998$ & $3,90^{\mathrm{c}}$ \\
\hline TM & 05/06/1999 & $2,75^{n}$ \\
\hline TM & 23/07/1999 & $2,78^{n}$ \\
\hline ETM+ & 17/09/1999 & $2,85^{n}$ \\
\hline ETM+ & 19/10/1999 & $2,80^{\mathrm{n}}$ \\
\hline $\mathrm{TM}$ & 12/11/1999 & $2,61^{n}$ \\
\hline $\mathrm{TM}$ & $26 / 08 / 2000$ & $3,19^{n}$ \\
\hline ETM+ & 03/09/2000 & $3,26^{n}$ \\
\hline TM & $01 / 01 / 2001$ & $2,74^{n}$ \\
\hline TM & $02 / 02 / 2001$ & $2,58^{n}$ \\
\hline TM & $25 / 05 / 2001$ & $2,64^{n}$ \\
\hline $\mathrm{TM}$ & $17 / 11 / 2001$ & $3,40^{n}$ \\
\hline ETM+ & $28 / 01 / 2002$ & $3,29^{n}$ \\
\hline $\mathrm{TM}$ & 09/03/2002 & $3,48^{n}$ \\
\hline ETM+ & 04/05/2002 & $4,26^{c}$ \\
\hline ETM+ & 09/09/2002 & $4,34^{\mathrm{c}}$ \\
\hline ETM+ & $25 / 09 / 2002$ & $4,34^{c}$ \\
\hline ETM+ & $12 / 11 / 2002$ & $4,03^{c}$ \\
\hline TM & $20 / 09 / 2003$ & $3,48^{n}$ \\
\hline
\end{tabular}

Fonte: baseado em Tassi (2008).

Segundo Giovannini (2004) a MAE $S$. giganteus não possui qualquer capacidade de sobrevivência prolongada em locais onde a lâmina de água tenha profundidade maior que 20 cm. No entanto, contrariando esta informação, os locais de ocorrência de $S$. giganteus ocuparam maior área na condição de cheia (Figuras $5 \mathrm{C}$ e F), com 5,92\% da área do Banhado do Taim (1.159,38 ha), concentrada, principalmente, na região leste da área de estudo, onde os níveis d'água eram superiores a $20 \mathrm{~cm}$. Ressalta-se que este alto valor de área de ocorrência de $S$. giganteus deveu-se, possivelmente, ao baixo número de imagens correspondentes a esta condição bem como à confusão espectral entre a planta úmida e lâmina de água.

Em um banhado na região Sul do Brasil, próximo à região desse estudo, Kafer et al. 
(2011) constataram que a predominância de $S$. constatada no Banhado do Taim, onde a espécie giganteus causa perda na riqueza e biodiveré pouco competitiva dentro do mesmo sidade de macrófitas. Esta observação não é

(Giovannini, 2004).

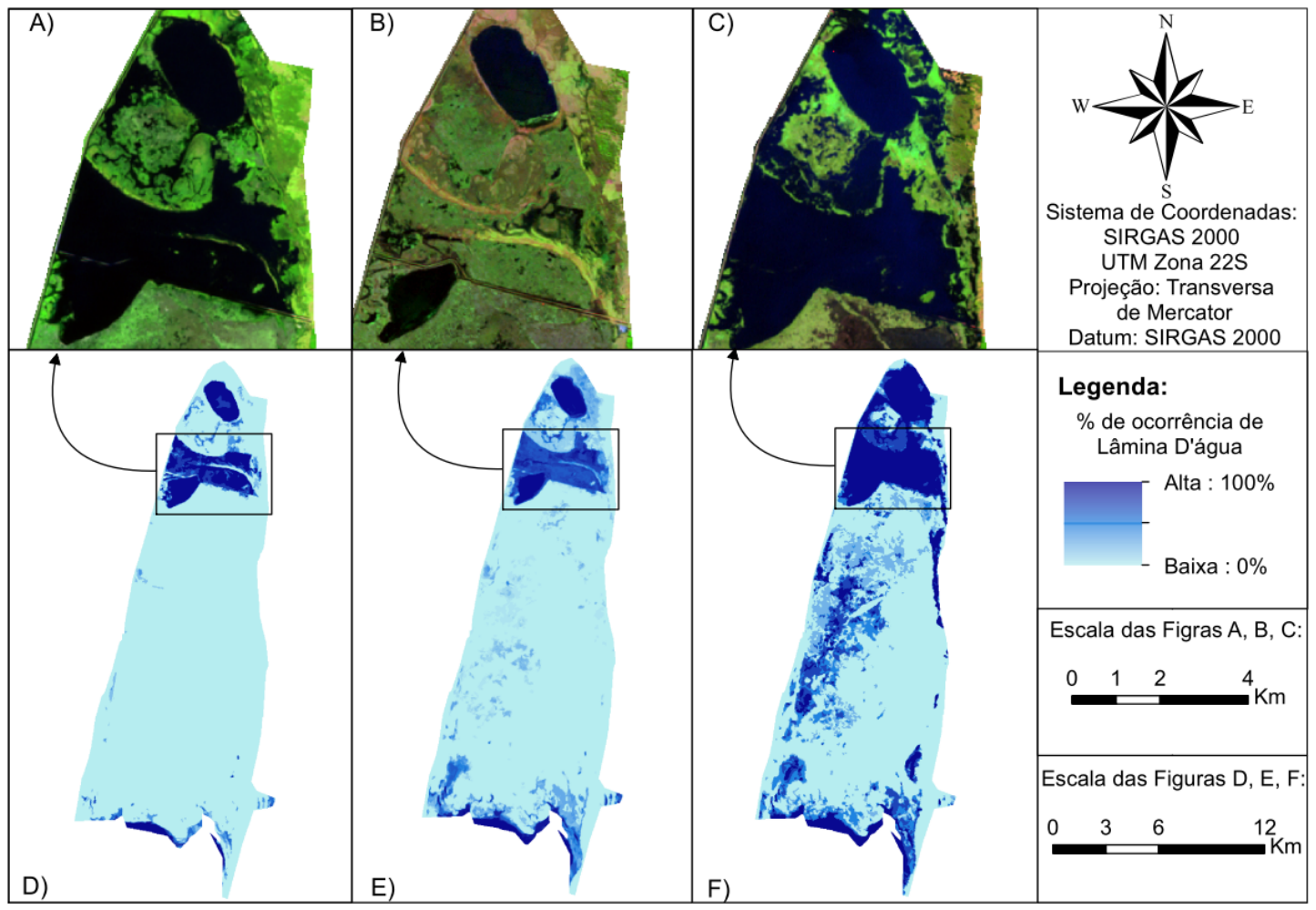

Figura 4 - Áreas de lâmina de água aparente por condição hidrológica: A) imagem de 19/10/99 composição RGB 543, representa uma seca; B) imagem de 06/07/87 composição RGB - 543, representa uma condição normal; C) imagem de 04/05/02 composição RGB - 543, representa uma cheia; D) ocorrência de lâmina na condição de seca; E) ocorrência de lâmina na condição de normal; F) ocorrência de lâmina na condição de cheia.

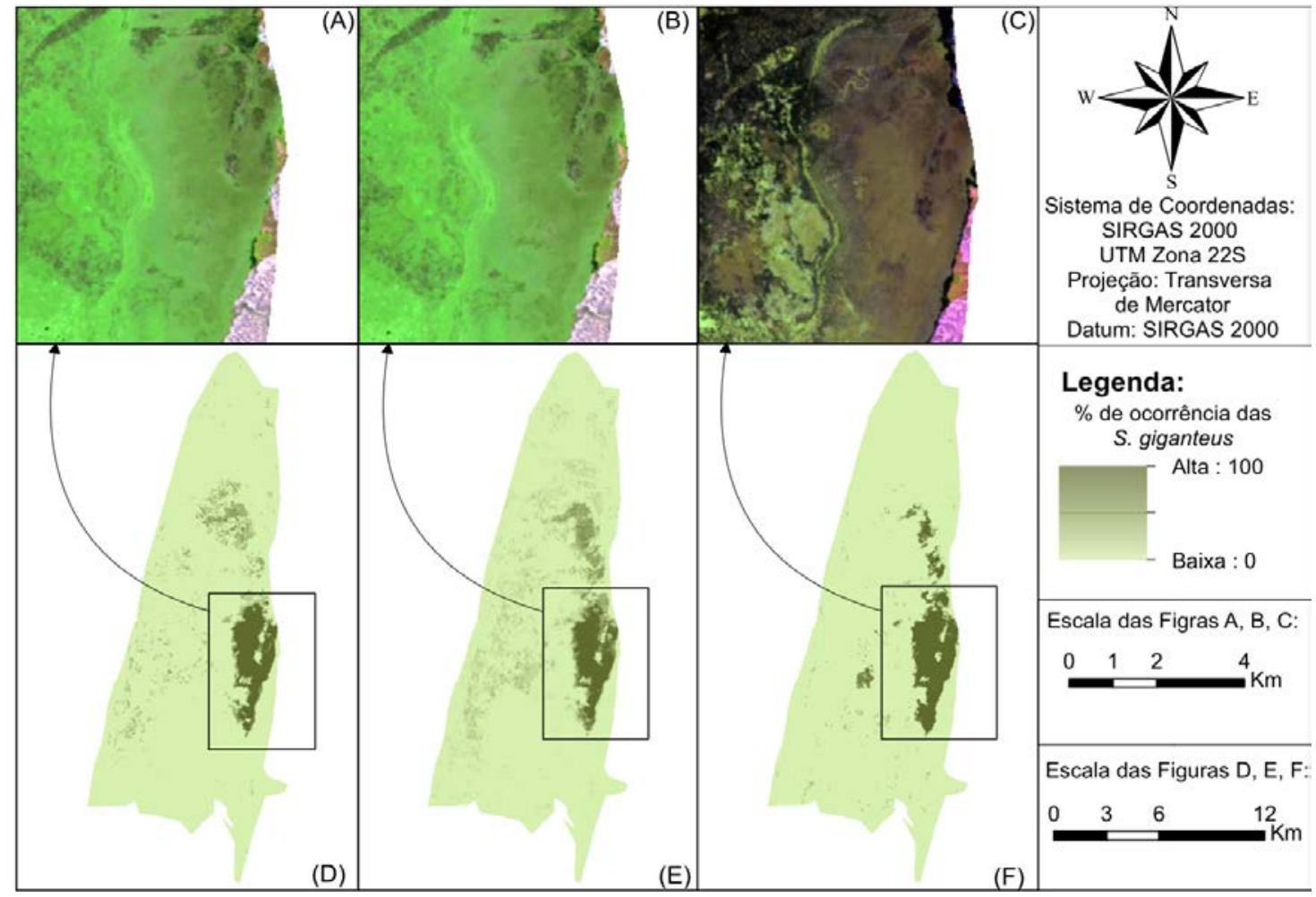

Figura 5 - Ocorrência de S. giganteus por condição hidrológica: A) imagem de 19/10/99 composição RGB - 543, representa uma seca; B) imagem de 19/10/99 composição RGB - 543, representa uma condição normal; C) imagem de 04/05/02 composição RGB - 543, representa uma cheia; D) ocorrência de S. giganteus na condição de seca; E) ocorrência de S. giganteus na condição normal; F) ocorrência de S. giganteus na condição de cheia. 
A espécie $S$. californicus tem seus estandes concentrados na parte central do Banhado, em uma região mais suscetível à inundação. Isso torna sua identificação difícil devido à confusão na resposta espectral desta macrófita, com a água e macrófitas flutuantes, principalmente nas épocas de cheia. Em razão disto foi impossibilitada a diferenciação entre água e $S$. californicus na condição de cheia, o que inviabilizou o cálculo da área correspondente a 80\% de permanência da macrófita nesta condição, sendo sua presença constatada em apenas $66 \%$ das imagens, como mostra a figuras $6 \mathrm{C}$ e $\mathrm{F}$.

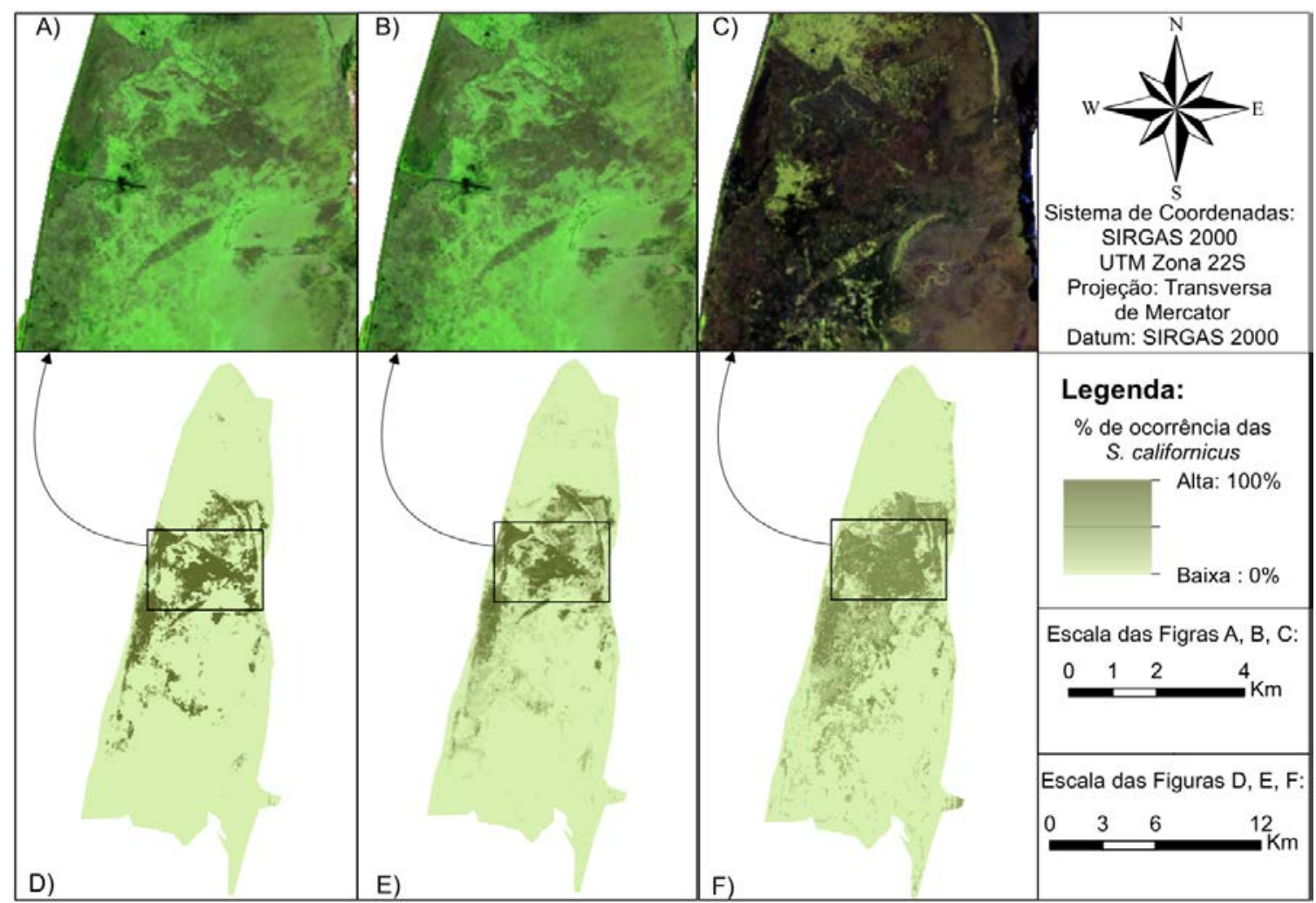

Figura 6 - Ocorrência de S. californicus por condição hidrológica: A) imagem de 19/10/99 composição RGB - 543, representa uma seca; B) imagem de 19/10/99 composição RGB - 543, representa uma condição normal; C) imagem de 04/05/02 composição RGB - 543, representa uma cheia; D) ocorrência de S. californicus na condição de seca; E) ocorrência de S. californicus na condição normal; F) ocorrência de S. californicus na condição de cheia.

O que propicia a permanência da macrófita $S$. californicus em locais mais profundos é sua alta resiliência a condições desfavoráveis. No entanto, para isso a espécie sofre transformações físicas como, por exemplo, o aumento do comprimento do caule para compensar as variações das lâminas da água (Kandus, 1999 apud Tassi, 2008; Herbst et al., 2011), investindo maior quantidade de energia no aumento do tamanho dos caules que na produção de um número maior destes. Esse fato também pode influenciar a resposta espectral desta macrófitas em satélites com resolução espacial igual ou menor que as do Landsat (30 metros) (Sakuma, 2008).

A espécie de MAE dominante no Banhado do Taim é a $Z$. bonariensis, e sua área de ocorrência em uma condição normal é de cerca de 4.507,82 ha (23,02\% da área do Banhado do Taim) (Figuras 7 B e E). A área de ocorrência máxima da $Z$. bonariensis foi de 5.781,49 ha em uma condição de seca (29,53\% do Banhado do Taim) (Figuras $7 \mathrm{~A}$ e D), enquanto na condição de cheia, verificou-se uma redução para 1.403,02 ha (7,16\% da área do Banhado do Taim) nas áreas desta espécie (Figuras 7 C e F), o que sugere que esta é a espécie mais prejudicada quando se tem um aumento nas lâminas d’água.

No entanto, a predominância desta espécie é compreendida, devido às características por ela apresentadas, pois possui alta capacidade de reprodução em situações adversas. Estudos relatam a relação inversa entre a sua densidade e a altura de seus estandes, a partir de sua borda para o interior indicando uma autorregulação da biomassa, o que possibilita sua expansão e reduz a competição por luz e nutrientes em seu interior. Aliado a essas adaptações, seu sucesso 


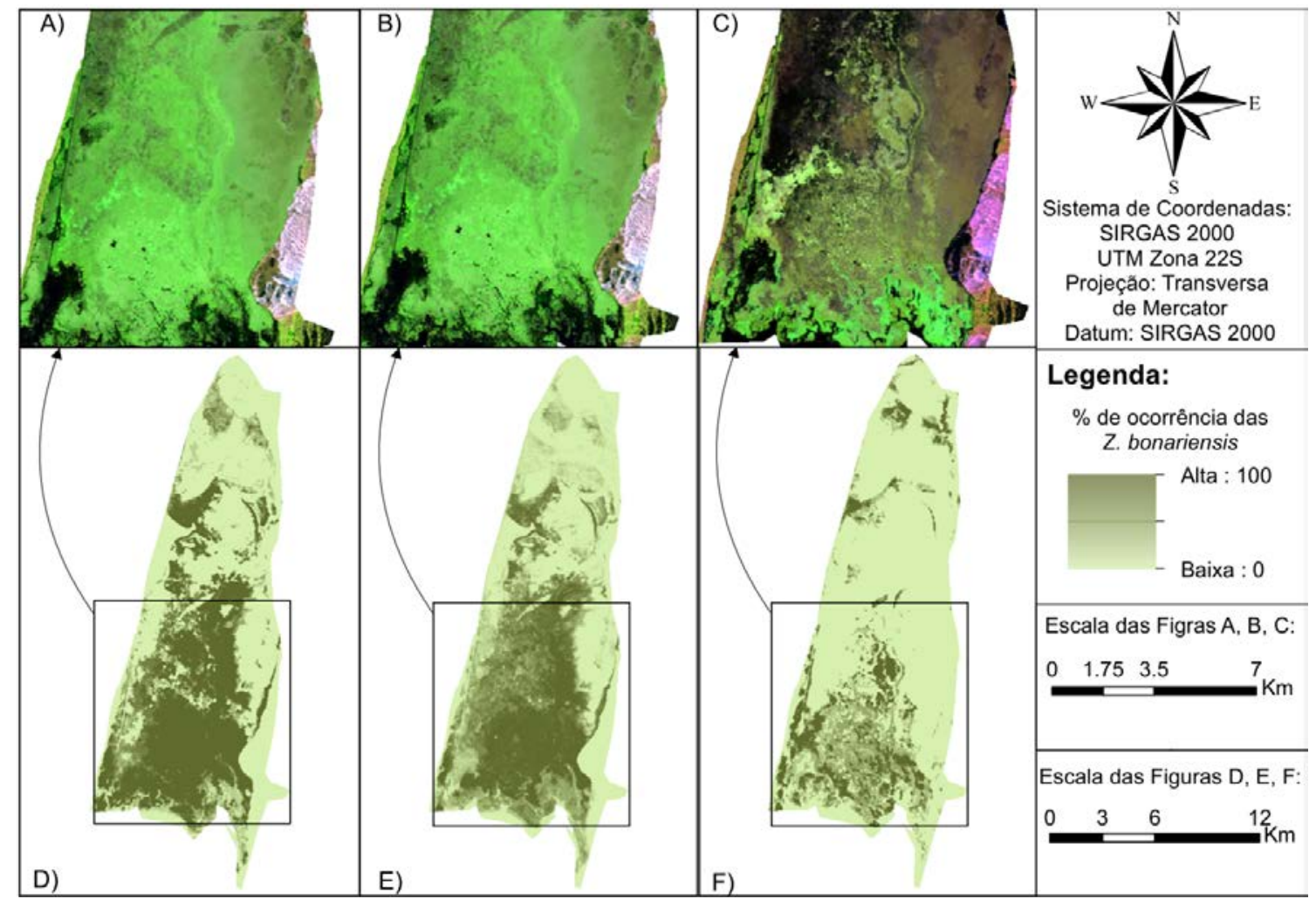

Figura 7 - Ocorrência de Z. bonariensis por condição hidrológica: A) imagem de 19/10/99 composição RGB - 543, representa uma seca; B) imagem de 19/10/99 composição RGB - 543, representa uma condição normal; C) imagem de 04/05/02 composição RGB - 543, representa uma cheia; D) ocorrência de Z. bonariensis na condição de seca; E) ocorrência de Z. bonariensis na condição normal; F) ocorrência de Z. bonariensis na condição de cheia.

No Banhado do Taim não foram encontrados indícios de perdas das MAE avaliadas durante a condição de seca. Este resultado vai ao encontro dos de Sah et al. (2013), que em estudo conduzido no Parque Nacional Everglades, nos Estados Unidos, não relataram perdas nas espécies estritamente pela condição de nível d'água baixo, mas ressaltam que esta condição torna as macrófitas mais vulneráveis à ocorrência de queimadas.

Todas as espécies apresentaram dificuldades em suas identificações, principalmente nas condições de cheia e seca. Como consequência da falta d'água, foram observadas alterações na resposta espectral de todas as espécies, o que causou maior dificuldade na separação entre planta e solo. Alterações semelhantes ocorreram devido ao excesso d'água, ocasionado pelo mascaramento da resposta espectral das macrófitas que ficam submersas ou quase submersas, dificultando a distinção dentre água e MAE.

Estas dificuldades impulsionam a continuidade de estudos que identifiquem melhores formas de classificar as MAE por meio das imagens de satélite, como o uso de índices de vegetação e outros derivados do SR (Zhao et al.,2009; Powell et al.,2014), para separar de melhor forma estes alvos.

Contudo, foi possível separar diferentes padrões de distribuição da vegetação para cada uma das três condições hidrológicas (seca, normal e cheia), conforme apresentado na figura 8. Com níveis d'água permanecendo nos valores considerados normais, o $S$. californicus e as $Z$. bonariensis obtiveram maior ocorrência na parte central do Banhado do Taim. Fato este devido à capacidade de adaptação destas MAEs a lâminas d'água mais elevada, comparadas às outras espécies encontradas no local (Figura 8B).

$\mathrm{Na}$ condição de cheia (Figura $8 \mathrm{C}$ ) houve maior área de ocorrência de S. californicus, o que na verdade pode ser atribuído à confusão espectral entre esta espécie e as macrófitas flutuantes, que com níveis d'água elevados, tendem a dominar o ambiente (Motta Marques et al., 1997). A confusão na resposta espectral também ocorre em relação à água, dificuldade que foi incontornável com o nível de resolução espectral e espacial utilizado no estudo. 

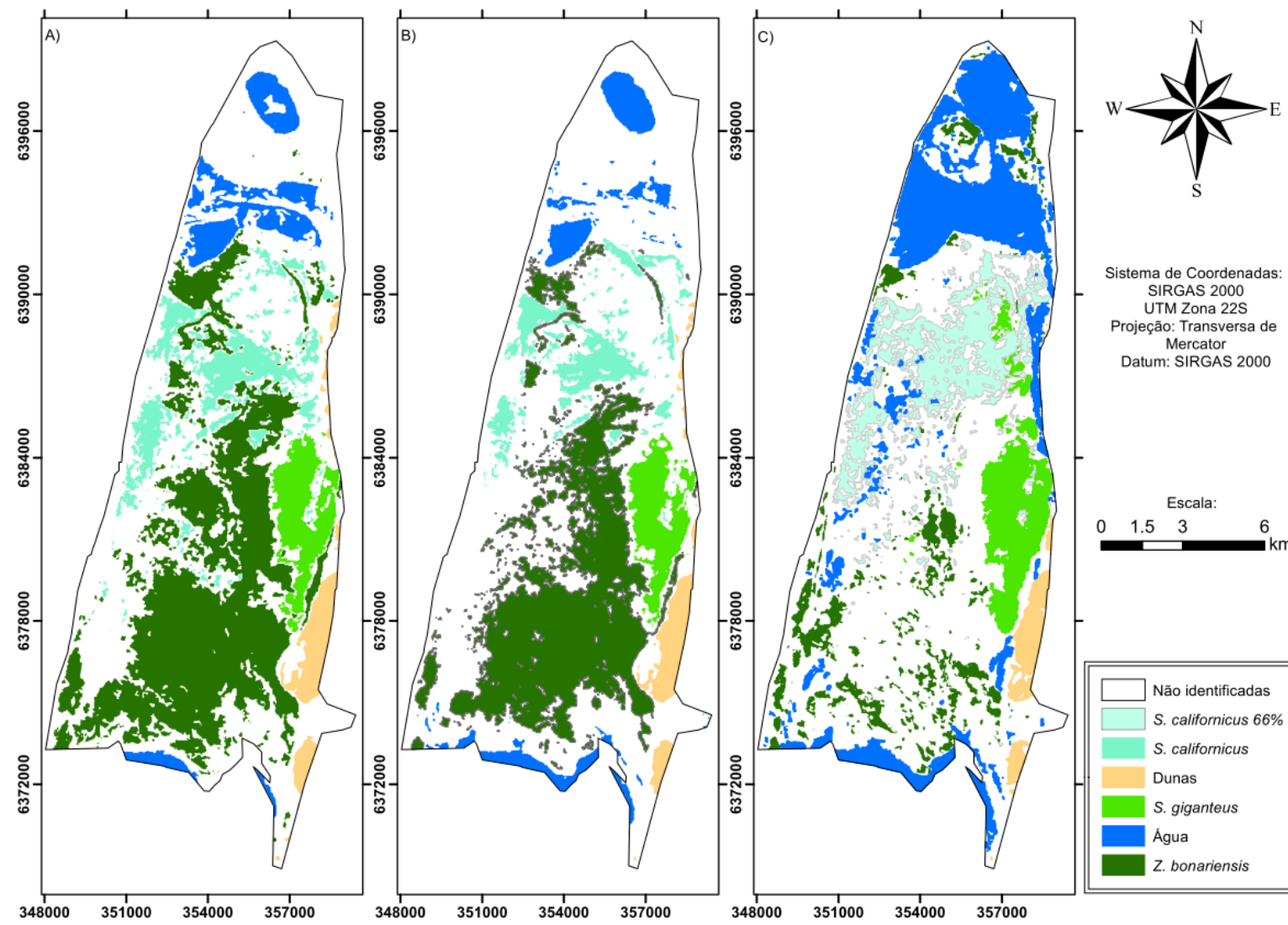

Sistema de Coordenadas: SIRGAS 2000
UTM Zona 22S Projeção: Transversa de Datum: SIRGAS 2000

Figura 8 - Padrão da vegetação por condição hidrológica. A) Seca; B) Normal; C) Cheia.

Com relação a um estudo prévio realizado por Guasselli (2005), foram relatadas áreas menores para o $S$. giganteus e $Z$. bonariensis, enquanto a área de ocorrência do $S$. californicus basicamente se manteve a mesma, assim como as áreas de lâmina de água. Acredita-se que a diferença nas áreas de ocorrência das duas espécies de MAE, se deva à metodologia mais conservadora empregada neste estudo, e o uso de trabalhos mais recentes desenvolvidos no Banhado do Taim que nortearam a identificação da região de ocorrência de cada MAE.

Os resultados aqui obtidos foram validados a partir da pesquisa realizada por Gayer et al. (1988), que não foi utilizada inicialmente como apoio na identificação das áreas de ocorrência de MAE. Esses autores verificaram que durante o período chuvoso, o Banhado do Taim torna-se totalmente alagado, e citam que durante o período de verão ocorre uma expansão das bordas da vegetação do Banhado do Taim. Este último aspecto não pôde ser confirmado neste estudo, visto que foram encontradas apenas duas imagens de seca no período de verão (Figura $8 \mathrm{~A}$ ), de um total de sete para a condição de seca.

A capacidade de recuperação das MAE estudadas deve-se, em grande parte, à existência de bancos de sementes. Segundo Shipley et al. (1989), como a germinação das sementes também depende da luz solar, o banco de sementes permanece adormecido até que os níveis d’água baixem e permitam o desenvolvimento destas, proporcionando condições para uma rápida recuperação da vegetação frente a perturbações.

\section{CONCLUSÕES}

Os resultados da análise da dinâmica espaçotemporal das macrófitas aquáticas emergentes no Banhado do Taim frente a diferentes níveis d'água demonstraram que a espécie $Z$. bonariensis domina a maior parte do Banhado do Taim; sua área de ocorrência tem uma forma triangular no sentido Sul-Norte na região central do Banhado do Taim. A região Centro-
Oeste do Banhado do Taim é ocupada predominantemente pelo $S$. californicus, enquanto na região Centro-Leste ocorre predominância do $S$. giganteus. A região Norte do Banhado do Taim apresentou maior limitação na identificação da MAE predominante, sendo observada no local a ocorrência de pequenos estandes com 
comportamento espectral muito semelhando ao da $Z$. bonariensis em algumas imagens.

$\mathrm{Na}$ condição de cheia foi constatada a ausência da macrófita $S$. californicus e uma significativa redução de $Z$. bonariensis, em imagens cujo histórico hidrológico indicava um período superior a sete meses sob níveis d'água maiores que $3,48 \mathrm{~m}$. A permanência das mesmas no local após o período crítico é creditada a sua capacidade de adaptação e recuperação frente a condições hidrológicas desfavoráveis. Apesar do S. giganteus ser uma espécie pouco tolerante a altos níveis d’água, por estar localizado em áreas de cotas topográficas mais altas, não apresentou redução expressiva em sua área de ocorrência, comparativamente às outras macrófitas.

Como consequência da condição hidrológica de seca, verificou-se um aumento nas áreas de ocorrências das três macrófitas, 33,5\% para o $S$. californicus, $7,5 \%$ para o S. giganteus e $28 \%$ para a Z. bonariensis, em relação à condição hidrológica normal, o que sugere que as espécies se beneficiam desta condição para aumentar a produção de biomassa.

Analisando os resultados encontrados (e desconsiderando limitações relacionadas ao escasso número de imagens em cada condição hidrológica, possibilidade de confusão espectral entre alvos e erros acumulados devido aos processos de modelagem do nível d'água), pode-se concluir que a condição hidrológica de nível d'água em torno do que é considerado normal (entre 2,11 e 3,69 m), é a que propicia a manutenção da alta biodiversidade e as condições naturais de competitividade entre as macrófitas estudadas.

A condição hidrológica de cheia apresentou maiores desafios no processo de classificação das imagens Landsat para a identificação das áreas de ocorrências das três MAE selecionadas, assim como na condição de seca. Portanto, sugere-se que em estudos futuros sejam utilizados sensores remotos de maior resolução espectral e espacial, com o intuito de minimizar o grau de confusão entre os tipos de vegetação e água, bem como a aferição da resposta espectral das MAE com o uso de dados radiométricos obtidos in situ por meio de sensores terrestres (espectrorradiômetro). Esta aferição citada foi impossibilitada neste trabalho, devido ao período de tomada das imagens (1984 até 2003), ser anterior à data de realização do estudo.

\section{AGRADECIMENTOS}

Os autores agradecem ao CNPq/CAPES pelo fomento ao desenvolvimento desta pesquisa.

\section{REFERÊNCIAS}

ANA - Agência Nacional das Águas. Cuidando das águas: soluções para melhorar a qualidade dos recursos hídricos. Agência Nacional de Águas/Programa das Nações Unidas para o Meio Ambiente. Brasília, DF, 152 p. 2011.

ANA - Agência Nacional das Águas. Conjuntura dos recursos hídricos no Brasil. Brasília, DF, 434 p. 2013.

AGOSTINHO, A. A.; THOMAZ, S. M.; MINETE-VERA, C. V.; WINEMILLER, K. O. Biodiversity in the high Paraná River floodplain. Biodiversity in wetlands: assessment, function and conservation, v. 1, p. 89-118. 2000.

ARAÚJO, A. S. F. \& MONTEIRO, R. T. R. Indicadores biológicos de qualidade do solo. Bioscience Journal, v. 23, n.3, p. 66-75. 2007.

ARMENTANO, T. V.; SAH, J. P.; ROSS, M. S.; JONES, D. T.; COOLEY, H. C.; SMITH, C. S. Rapid responses of vegetation to hydrological changes in Taylor Slough, Everglades National Park, Florida, USA. Hydrobiologia, v. 569, n. 1, p. 293-309, 2006.

ANTUNES, C.; CORREIA O.; SILVA, J. M.; CRUCES, A.; FREITAS, M. C.; BRANQUINHO, C. Factors involved in spatiotemporal dynamics of submerged macrophytes in a Portuguese coastal lagoon under Mediterranean climate. Estuarine, Coastal and Shelf Science, v. 110, p. 93-100, 2012.

BURGER, M. I. Situação e Ações Prioritárias para a Conservação de Banhados e Áreas Úmidas da Zona Costeira. Porto Alegre: Fundação Zoobotânica do RS, 60p., 2000.

BURGER, M. I. \& RAMOS, R. A. Áreas Importantes para Conservação na Planície Costeira do Rio Grande do Sul. In:
BECKER, F.G.; MOURA, L; RAMOS, R.A (Org.) Biodiversidade. Regiões da Lagoa do Casamento e dos Butiazais de Tapes, Planície Costeira do Rio Grande do Sul. Brasília: Ministério do Meio Ambiente, p. 46-56, 2007.

CARVALHO, T. M. \& CARVALHO, C. M. Sistemas de informações geográficas aplicadas à descrição de habitats. Acta Scientiarum. Human and Socieal Sciences, vol. 34, n. 1, p. 79-90, 2012.

CHOMENKO, L. Recursos hídricos e áreas úmidas: ambientes a serem preservados. In.: ZAKRZEVSKI, S. B. (Org.). Conservação e uso sustentável da água: múltiplos olhares. Erechim: EdiFapes, RS, p. 33-48, 2007

CORREA, F.; GARCIA, A. M.; BEMVENUTI, M DE. A.; VIEIRA, J. P. Pisces, Gymnotiformes, Hypopomidae, Brachyhypopomus gauderio Giora and Malabarba, 2009: New species record at Taim Ecological Reserve, South Brazil. Check List, v. 7, n. 1, p. 19-20, 2011.

CONGEDO, L.; MUNAFO, M.; MACCHI S. Investigating the Relationship between Land Cover and Vulnerability to Climate Change in Dar es Salaam. Working Paper, Rome: Sapienza University. 2003. Disp. em: http: <//www.planning4adaptation.eu/Docs/papers/08_NWPDoM_for_LCC_in_Dar_using_Landsat_Imagery.pdf> Acesso em: 15 jan 2016.

ESTEVES, F. DE A. Fundamentos de Limnologia. $2^{\text {a }}$ Edição. Editora Interciência, Rio de Janeiro, 602 p. 1998.

FOTI, R.; DEL JESUS, M.; RINALDO, A.; RODRIGUEZITURBE, I. Signs of critical transition in the Everglades 
wetlands in response to climate and anthropogenic changes. PNAS, Washington, vol. 110, n. 16, p. 6296-6300, 2013.

FREEDMAN, B. \& LACOUL, P. Environmental influences on aquatic plants in freshwater ecosystems. Environmental Review, v. 14, n. 2, p. 89-136, 2006.

FRAGAL, E. H.; ALVES, F. C.; SOUZA FILHO E. E. A Influência do nível fluviométrico sobre as variações de área de água e da cobertura vegetal na planície do alto rio Paraná. Revista Brasileira de Geomorfologia, v.13, n.3, p.299-310. 2012.

FERREIRA, T. F. Ecologia e aplicabilidade de métodos para avaliação da produção primária de Zizaniopsis bonariensis: uma macrófita aquática emergente, no Sistema Hidrológico do Taim, RS. Porto Alegre, 2005. 135p. Dissertação (Mestrado em Ecologia) - Instituto de Biociências, Universidade Federal do rio Grande do Sul.

FERREIRA, T. F.; VAN NES, E.; MOTTA-MARQUES, D. Continuous growth of the giant grass Zizaniopsis bonariensis in subtropical wetlands. Freshwater Biology, v. 54, n. 2, p. 321-330, 2009.

GUASSELLI, L. A. Dinâmica da Vegetação no Banhado do Taim, RS. Porto Alegre, 2005. 157 p. Tese (Doutorado em Recursos Hídricos e Saneamento Ambiental), Instituto de Pesquisas Hidráulicas, Universidade Federal do Rio Grande do Sul.

GIOVANNINI, S. G. T. Estudo de Variabilidade da Vegetação no Banhado do Taim. Porto Alegre, 2004. 266 p. Tese (Doutorado em Recursos Hídricos e Saneamento Ambiental), Instituto de Pesquisas Hidráulicas, Universidade Federal do Rio Grande do Sul.

GARCIA, A. M.; HOEINGHAUS, D. J.; VIEIRA, J. P.; WINEMILLER, K. O.; MOTTA-MARQUES, D. M. L.; BEMVENUTI, M. A. Preliminary examination of food web structure of Nicola Lake (Taim Hydrological System, south Brazil) using dual $\mathrm{C}$ and $\mathrm{N}$ stable isotope analyses. Neotropical Ichthyology, v. 4, n. 2, p. 279-284, 2006.

GAYER, S. M. P.; KRAUSE, L.; GOMES, N. Lista preliminar dos anfíbios da Estação Ecológica do Taim. Revista Brasileira de Zoologia, v. 5, n. 3, p. 419-425. 1988.

HERBST, D.; FUENTES, E. V.; SAITO, E. N.; TSUDA, É. T.; SALDANHA, J. H.; SORIANO-SIERRA, E. J. Efeito da profundidade sobre a altura e número de indivíduos da população de Schoenoplectus californicus, no parque municipal da Lagoa do Peri, Florianópolis, SC. Ecologia de Campo UFSC, p. 133-142, 2011.

IPCC, 2007: Climate Change 2007: Synthesis Report. Contribution of Working Groups I, II and III to the Fourth Assessment Report of the Intergovernmental Panel on Climate Change. Core Writing Team, Pachauri, R.K and Reisinger, A.(eds.)]. IPCC, Geneva, Switzerland, 104 pp.

IPCC, 2014: Climate Change 2014. Synthesis Report. Summary for Policymakers. 2014. Disponível em: $<$ http://www.ipcc.ch/report/ar5/syr/>. Acesso em: 10 dez. 2015.

KAFER, D. S.; COLARES, I. G.; HEFLER, S. M. Composição florística e fitossociológica de macrófitas aquáticas em um banhado continental em Rio Grande, RS, Brasil. Rodriguésia, v. 62, n. 4, p. 835-846, 2011.

MOTTA-MARQUES, D. M. L.; IRGANG, B.; GIOVANNINI, S. G. T. A importância do hidroperíodo no gerenciamento de água em terras úmidas (wetlands) com uso múltiplo - o caso da Estação Ecológica do Taim. In: XII SIMPÓSIO DE RECURSOS HÍDRICOS, XII SBRH, Vitória, 1997. Anais...Vitória: ABRH, 1997.

MORAES, A. R. Indicadores para a caracterização de serviços ambientais de áreas úmidas. Estudo de caso: $\mathrm{A}$ área de proteção ambiental das ilhas e várzeas do Rio Paraná. Brasilia. 2011. 216 p. Tese (Doutorado em Tecnologia Ambiental e Recursos Hídricos), Departamento de Engenharia Civil e Ambiental, Universidade de Brasília.

MESQUITA, F. D. O.; ALVES, A. D. S.; MALHEIROS, S. M. M.; SILVA, P. C. M. D.; SANTOS, W. D. O.; BATISTA, R.
O. Uso do Sensoriamento Remoto Para Avaliação da Distribuição Espacial e Quantificação de Macrófitas na Barragem Umari-Upanema, RN. Agropecuária Científica no Semiarido, v. 9, n. 2, p. 102-109, 2013.

PANESSA, R.; PALO JR., H.; TRESCA, D. Estação Ecológica do Taim. Projeto cultural Lloyds Bank. São Paulo: Empresa das Artes, 44 p, 1989.

PAZ, A. R. Análise dos principais fatores intervenientes no comportamento hidrodinâmico do banhado do Taim (RS). Porto Alegre, 2003. 176 p. Dissertação. (Mestrado em Recursos Hídricos e Saneamento Ambiental), Instituto de Pesquisas Hidráulicas, Universidade Federal do Rio Grande do Sul.

PACHAURI, R. \& MEYER, L. Climate Change 2014: Synthesis Report. Contribution of Working Groups I, II and III to the Fifth Assessment Report of the Intergovernmental Panel on Climate Change. Geneva, Switzerland, IPCC, 151 p, 2014.

POTT, A.; POTT, V. J.; MOREIRA, S. N.; FERREIRA, F. A. Macrófitas aquáticas do Pantanal e de outras áreas úmidas em Mato Grosso do Sul. Heringeriana, v. 6, n. 1, p. 72-75, 2012.

POWELL, S. J.; JAKEMAN, A.; CROKE, B. Can NDVI response indicate the effective flood extent in macrophyte dominated floodplain wetlands ?. Ecological Indicators, v. 45, p. 486-493, 2014.

ROSSATO, M. S. Os Climas do Rio Grande do Sul: Variabilidade, Tendências e Tipologia. Porto Alegre, 2011. 253 p. Tese (Doutorado em Geografia), Instituto de Geociências, Universidade Federal do Rio Grande do Sul.

SAH, J. P.; ROSS, M. S.; SAHA, S.; MINCHIN, P.; SADLE, J. Trajectories of vegetation response to water management in Taylor Slough, Everglades National Park, Florida. Wetlands, v. 34, n. 1, p. 65-79, 2013.

SILVA, T. S. F.; COSTA, M. P. F.; MELACK, J. M. Spatial and temporal variability of macrophyte cover and productivity in the eastern Amazon floodplain: A remote sensing approach. Remote Sensing of Environment, v. 114, n. 9, p. 1998-2010, 2010.

SAKUMA, T. Biomassa e taxa de crescimento da macrófita aquática emergente scirpus californicus (c.a.mey) steud na margem Leste da lagoa do peri (Ilha de Santa Catarina, SC, Brasil). Florianópolis, 2008. 42p Trabalho de conclusão de curso (Bacharel em ciências biológicas), Universidade Federal de Santa Catarina.

SETE, L. R. Relações entre Estação Ecológica do Taim e Comunidade Local: Conflitos e Cooperação. Santa Maria, 2010. 127p. Dissertação (Mestrado em Extensão Rural), Centro de Ciências Rurais, Universidade Federal de Santa Maria.

SHIPLEY, B.; KEDDY, P. A.; MOORE, D. R. J.; LEMKY, K. Regeneration and establishment strategies of emergent macrophytes. The Journal of Ecology, v. 77, n.4, p. 10931110, 1989.

SILVA, R. T. \& PORTO, M. F. A. Gestão urbana e gestão das águas: caminhos da integração. Estudos avançados v. 17, n. 47, p. 129-145, 2003. Disp. em:<http://www.scielo.br/scielo. php?script=sci_arttext\&pid=S0103-40142003000100007\& lng=en\&nrm=iso>. Acesso em: 22 Aug. 2015.

SIMON, A. L. H. \& SILVA, P. F. Análise geomorfológica da planície lagunar sob influência do canal São Gonçalo - Rio Grande do Sul - Brasil. Geociências, v. 34, n. 4, p.749-767, 2015.

TASSI, R. Gerenciamento Hidroambiental de Terras Úmidas. Porto Alegre, 2008. 240p. Tese (Doutorado em Recursos Hídricos e Saneamento Ambiental), Instituto de Pesquisas Hidráulicas, Universidade Federal do Rio Grande do Sul.

TASSI, R.; BRAVO, R. M.; MARQUES, D. M.; CARDOSO, A. Avaliação de projeção de anomalias de temperatura e precipitação em cenários climáticos futuros na região do sistema hidrológico do Taim, RS. In: SIMPÓSIO 
BRASILEIRO DE RECURSOS HÍDRICOS, XIX, Maceió, 2011. Anais... Maceió: ABRH, 2011.

TODD, M. J.; MUNEEPEERAKUL, R.; PUMO, D.; AZAELE, S.; MIRALLES-WILHELM, F.; RINALDO, A.; RODRIGUEZ-ITURBE, I. Hydrological drivers of wetland vegetation community distribution within Everglades National Park, Florida. Advances in Water Resources, v. 33, n. 10, p. 1279-1289, 2010.

TUNDISI, J. G. Novas perspectivas para a gestão de recursos hídricos. REVISTA USP, n.70, p. 24-35, junho/agosto 2006

VILLANUEVA, A. Modelo Hidrodinâmico-Hidrológico do Banhado do Taim. In: MOTTA - MARQUES, D da (coord.). Sistema Hidrológico do Taim: projeto integrado UFRGS, FURGS, FZB. Porto Alegre. 8 p, 2003. (CNPq. Pesquisas Ecológicas de Longa Duração. Sítio 7).

XAVIER, R. A. Índices de Adequabilidade de Habitat como Subsídio ao Gerenciamento dos Recursos Hídricos do Banhado Taim. Santa Maria, 2015. 131p. Dissertação (Mestrado em Engenharia Ambiental), Centro de Tecnologia, Universidade Federal de Santa Maria.
ZEDLER, J. B. \& KERCHER, S. Wetland Resources: Status, Trends, Ecosystem Services, and Restorability. Annual Review of Environment and Resources, v. 30, p. 39-74. 2005.

ZHAO, B.; YAN, Y.; GUO, H.; HE, M.; GU, Y.; LI, B. Monitoring rapid vegetation succession in estuarine wetland using time series MODIS-based indicators: an application in the Yangtze River Delta area. Ecological Indicators, v. 9, n. 2, p. 346-356, 2009.

WARD, D. P.; PETTY, A.; SETTERFIELD, S. A.; DOUGLAS, M. M.; FERDINANDS, K; HAMILTON, S. K; PHINN, S. Floodplain inundation and vegetation dynamics in the Alligator Rivers region (Kakadu) of northern Australia assessed using optical and radar remote sensing. Remote Sensing of Environment, v. 147, p. 43-55, 2014.

Submetido em 18 de novembro de 2016 Aceito em 7 de março de 2017 